\title{
TIME BUDGET PRESSURE ON THE RELATION BETWEEN PUBLIC TRUST AND AUDITOR INDEPENDENCE IN PUBLIC ACCOUNTING FIRM
}

\author{
Andi Ina Yustina ${ }^{1}$, Imas Nur Islami ${ }^{1}$ \\ 1 Universitas Presiden, Cikarang - Indonesia \\ a.inayustina@gmail.com
}

\begin{tabular}{ll}
\hline INFO ARTIKEL & ABSTRAK/ABSTRACT \\
\hline Histori Artikel : & The number of cases that occur involving the auditor or \\
Tgl. Masuk: 13 September 2019 & accountant raises a big question mark in the community \\
Tgl. Diterima: 28 September 2019 & about the responsibility of the auditor. The literature \\
Tersedia Online : 30 September 2019 & related to auditor behavior has been discussed by \\
\hline Keywords: & researchers to look for several possible causes of fraud. \\
Public Trust, Budget Pressure, & Although based on the AICPA rules that an auditor must \\
Independence, Auditor, Public & have integrity, independence, serve the public, and have \\
Accounting Firm & a level of trust in the public but the demands of work as \\
& an auditor make it very vulnerable to stress. The \\
& purpose of this study is to examine the role of time \\
budget pressures in weakening public trust and auditor \\
independence. This research will use quantitative \\
methods with data collection methods by the survey. A \\
total of 87 questionnaires collected from auditors \\
working at Big 4 and Non-Big 4 . Public Accountant \\
Firms. The test was conducted using SEM-PLS. The \\
results of this study indicate that time budget pressure is \\
not influence to auditor independence. However, public \\
trust is proven to have a relationship with auditor \\
independence.
\end{tabular}

\section{PENDAHULUAN}

Menurut AICPA pasal 101, independensi merupakan karakter yang sangat penting yang harus dimiliki oleh seorang auditor (AICPA, 1997). Independensi auditor diasumsikan sebagai integritas, kejujuran, dan objektivitas, termasuk juga didalamnya adalah kebebasan dalam mereview dokumen audit yang didasarkan oleh aturan-aturan pengauditan (Hudaib \& Haniffa, 2009). Laporan keuangan harus terbebas dari salah saji. Persyaratan independensi auditor timbul dari kebutuhan untuk menetapkan auditor sebagai "wasit" yang dapat menilai secara obyektif dalam bekerja (Falk dkk. 1999), serta memberikan pendapat independen tanpa intervensi dari pihak manapun atas penyajian laporan keuangan perusahaan yang andal (Moore dkk. 2006). Bazerman dkk. (1997), mengatakan bahwa independensi yang menjadi karakter wajib auditor memiliki tanggung jawab untuk memberikan informasi penting kepada pengguna eksternal laporan keuangan. 
Penelitian

terdahulu

mengungkapkan bahwa independensi auditor terdiri dari dua hal: independensi dalam fakta (independence in fact) dan independensi dalam tampilan (independence in appearance). Independensi dalam fakta berarti auditor menyatakan pendapat dalam laporan audit yang tidak terpengaruh oleh bias pribadi (Arens dkk. 2002), sedangkan independensi dalam tampilan berarti mengharapkan auditor untuk menghindari situasi yang mungkin menyebabkan orang lain berargumen bahwa auditor tidak mempertahankan sikap objektif (Porter dkk. 2003). Sementara itu, auditor dapat gagal dalam melakukan tanggung jawab mereka. Jatuhnya Enron, WorldCom, dan Tyco adalah beberapa kasus yang melibatkan akuntabilitas auditor untuk memverifikasi laporan keuangan yang menyesatkan. Akibatnya, kepercayaan publik kepada lembaga publik mulai memudar (Bazerman dkk. 1997). Investor, investor potensial, regulator, kreditor, karyawan, dan pengguna eksternal lainnya, bergantung pada laporan keuangan yang diaudit. Mereka membuat keputusan berdasarkan informasi mengenai kondisi keuangan perusahaan yang disiapkan dan dikeluarkan oleh manajer perusahaan (Bazerman dkk. 1997). Oleh karena itu, laporan keuangan yang telah diaudit sangat penting bagi pihak internal dan eksternal perusahaan (Moore dkk. 2006). Kehadiran kejujuran dan integritas aditor sangatlah diperlukan. Auditor tidak hanya harus dapat dipercaya, tetapi ia juga harus credible (Duska dkk. 2011).

Dalam menjalani tugas dan tanggung jawab auditor, ketepatan dan keandalan dalam membuat laporan audit sangatlah dibutuhkan. Untuk memenuhi hal tersebut, auditor memiliki anggaran waktu (Otley \& Pierce, 1996; Pierce \& Sweeney, 2004). Anggaran waktu menciptakan ketegangan di lingkungan kerja auditor manakala mereka harus memenuhi anggaran waktu tersebut dan disaat yang sama tuntutan laporan audit yang akuntanbel harus terpenuhi.
McNair (1991) berpendapat bahwa anggaran waktu memiliki potensi untuk menciptakan tekanan kerja auditor. Stres yang berlangsung terus menerus oleh auditor, dapat berpotensi mengurangi kualitas kerja audit dan meningkatkan turnover (Cooper, dkk. 2001). Beberapa peneliti lebih lanjut melaporkan efek lain dari tekanan anggaran waktu. Studi sebelumnya sepakat bahwa tekanan anggaran waktu berhubungan positif dengan perilaku audit disfungsional (Otley \& Pierce, 1996; Pierce \& Sweeney, 2004; Svanberg \& Öhman, 2013). Berdasarkan hasil penelitian sebelumnya, dapat dikatakan bahwa ketika tekanan anggaran waktu meningkat maka kemungkinan auditor akan melakukan perilaku yang menyimpang yang dampaknya dapat berupa gangguan terhadap independensinya meskipun kepercayaan publik memberikan dukungan yang maksimal. Oleh karena itu, penelitian ini akan menguji apakah tekanan anggaran waktu yang diberikan kepada auditor akan melemahkan kepercayaan publik terhadap independensi auditor.

\section{KERANGKA TEORITIS DAN PENGEMBANGAN HIPOTESIS}

\section{Kepercayaan Publik}

Zand (1972) menekankan tentang aspek kerentanan kepercayaan dengan membagi menjadi dua yaitu perilaku individu dan harapan individu. Reaksinya adalah menyerahnya kontrol, yang dia sebut "keputusan untuk percaya." Keputusan ini dipandu oleh sifat masalah dan oleh harapan hasilnya. Keyakinan secara implisit identik dengan kepercayaan, tetapi yang penting bagi Zand adalah melepaskan kontrol atas masalah ini. Kemudian Zand (1972) memperluas definisi pertama kepercayaan. Kepercayaan, ia menyarankan sebagai kesediaan satu orang untuk meningkatkan kerentanannya 
terhadap tindakan orang lain yang perilakunya tidak dapat ia kendalikan. Dia percaya bahwa kepercayaan melampaui harapan hasil di bawah kondisi ketidakpastian terhadap ekspektasi perilaku di bawah kondisi kerentanan.

Butler \& Cantrell (1984) menjelaskan sifat interpersonal kepercayaan sebagai syarat kerja sama tetapi menambahkan faktor rumit ketidaksetaraan dalam posisi. Mereka memeriksa dua karya sebelumnya yang berhubungan dengan hubungan atasan / bawahan dalam manajemen dan mengusulkan lima komponen kepercayaan atau karakteristik spesifik dari orang-orang:

1. Integritas - reputasi untuk kejujuran dan kebenaran pada bagian dari individu yang dipercaya.

2. Kompetensi - pengetahuan teknis dan keterampilan interpersonal yang diperlukan untuk melakukan pekerjaan.

3. Konsistensi - keandalan, prediktabilitas, dan penilaian yang baik dalam menangani situasi.

4. Loyalitas - kesediaan untuk melindungi, mendukung, dan mendorong orang lain.

5. Keterbukaan - aksesibilitas mental, atau kesediaan untuk berbagi ide dan informasi secara bebas dengan orang lain.

Definisi kepercayaan yang diberikan oleh buku berjudul Kepercayaan dan Timbal Balik oleh Elinor \& James (2013) mendefinisikan kepercayaan sebagai 'kemauan untuk mengambil risiko tentang orang lain dengan harapan bahwa orang lain akan membalasnya.' Pandangan ini membatasi tindakan mempercayai tindakan kerja sama, memberikan kontribusi, mempertahankan sejumlah biaya mengingat keuntungan masa depan yang bergantung, dalam kerangka strategis, juga pada perilaku pihak lain; dan itu membatasi harapan dengan harapan timbal balik (Elinor \& James, 2003).

\section{Tekanan Anggaran Waktu}

Tekanan anggaran waktu disajikan ketika perusahaan audit gagal menyelesaikan tugas audit khusus karena kurangnya jumlah waktu yang dialokasikan, sementara waktu tenggat waktu tekanan hadir ketika auditor menemukan kesulitan untuk menyelesaikan tugas audit dengan tenggat waktu tertentu (Svanstrom, 2016). Anggaran waktu audit dianggap sebagai dasar operasional yang penting dalam perusahaan akuntan publik (McNair, 1991). Selalu ada trade-off antara waktu yang dihabiskan untuk mengaudit dengan biaya kinerja itu (Otley \& Pierce, 1996; Pierce \& Seeney, 2004; Liyanarachchi \& McNamara, 2007; Etteredge et al., 2008). Ini berarti bahwa jumlah, sifat, dan waktu prosedur audit harus diimbangi dengan sumber daya yang dialokasikan untuk menyelesaikan tugas audit khusus (Svanstrom, 2016).

Cook \& Kelly (1991) menemukan bahwa penyebab paling umum dari tekanan anggaran waktu adalah tekanan biaya dari klien. Sebagai konsekuensinya, auditor menanggapi TBP dengan salah satu dari dua cara. Pertama, auditor bereaksi secara fungsional terhadap TBP dengan bekerja lebih keras (Otley \& Pierce, 1996); menuntut dan memperoleh peningkatan anggaran waktu dari para manajer (Cook \& Kelley, 1991; Coram dkk. 2003); berkonsentrasi pada informasi yang relevan (Glover, 1997); last but not least dengan menggunakan teknik audit yang lebih efisien (Coram dkk. 2003). Kedua adalah bereaksi disfungsional dengan 
melakukan tindakan RAQ atau underreporting time (URT).

Namun, tidak semua auditor akan bertindak secara praktis dan akan memilih perilaku disfungsional sebagai jalan keluar. Karena anggaran waktu mempengaruhi pengembangan karir dan kendala lainnya, (Pierce \& Sweeney, 2004; Gundry \& Liyanarachchi, 2007). Temuan menunjukkan bahwa tekanan anggaran waktu dapat memiliki efek yang berlawanan pada kualitas audit (Kelley \& Margheim, 1990; Otley \& Pierce, 1996, Coram dkk. 2003). Ini konsisten dengan argumen dari Otley \& Pierce (1996) bahwa di bawah tekanan anggaran waktu, auditor akan cenderung berperilaku tidak profesional dan lebih cenderung melakukan perilaku disfungsional.

\section{Independensi Auditor}

Berdasarkan Dewan Standar Etika Internasional untuk Akuntan (IESBA) ada dua komponen independensi, yaitu sebagai berikut (IESBA, 2012):

\section{Kemandirian Pikiran}

Kemandirian pikiran kadang-kadang disebut sebagai kemerdekaan. Ini berarti auditor memiliki memori independen yang memungkinkan ekspresi kesimpulan yang bebas dari pengaruh untuk mengkompromikan penilaian profesional. Auditor bebas untuk bertindak dengan integritas dan menerapkan objektivitas dan skeptisisme profesional dalam menjalankan profesinya.

\section{Kemandirian Penampilan}

Menghindari fakta atau keadaan apa pun yang dapat disimpulkan oleh pihak ketiga bahwa firma audit atau anggota integritas, objektivitas, atau skeptisisme tim audit telah dikompromikan berdasarkan fakta dan keadaan tertentu.
Meningkatkan independensi auditor adalah wajib bagi setiap auditor untuk menghasilkan pelaporan keuangan yang dapat diandalkan. Salah satu caranya adalah mengubah setidaknya mitra audit perusahaan secara teratur (Mohammed \& Habib, 2013). Mereka berspekulasi jika auditor memiliki keterlibatan panjang dengan klien maka tidak mengherankan jika efek bias pada bukti bisa muncul. Ini disediakan dengan bukti oleh Carey \& Simnet (2006) yang auditor lebih lama bekerja sama dengan klien mereka, independensi auditor yang lebih besar terganggu. Dengan demikian, beberapa negara, termasuk Indonesia, membatasi waktu keterlibatan. Cara lain untuk meningkatkan independensi auditor adalah dengan memahami perilaku auditor yang dapat merusak independensi (Shaub, 2015). Penelitiannya menyebutkan beberapa perilaku auditor, seperti kepercayaan, advokasi, dan kepentingan pribadi, dapat mempengaruhi independensi. Jadi, jika auditor memiliki pemahaman yang lebih baik dari mereka, itu bisa meningkatkan independensi auditor.

\section{Pengembangan Hipotesis}

\section{Hubungan antara Kepercayaan dengan Independensi Auditor}

Sebagian besar penilaian dan proses pengambilan keputusan terkait dengan kinerja ekonomi masa depan akan didasarkan pada laporan keuangan yang telah dipublikasikan untuk pihak eksternal. Dalam hal ini, peran kepercayaan publik menjadi sangat penting karena ikut serta dalam memahami informasi keuangan. Untuk meningkatkan keandalan informasi yang diperoleh, auditor perlu melakukan pemeriksaan laporan keuangan sebelum disajikan kepada pihak eksternal. Sebagai pihak eksternal, publik percaya bahwa auditor bekerja berdasarkan independensi 
menjangkau area yang lebih luas (Sekaran \& Bougie, 2013). Peneliti akan mengirim link pertanyaan ke email pribadi auditor sehingga memberikan keyakinan kepada peneliti bahwa kuesioner akan terisi oleh subjek peneliti yang sesungguhnya.

\section{Pengukuran Variabel}

Variabel independen dari penelitian ini adalah kepercayaan publik akan diukur dengan menggunakan pertanyaan yang diadaptasi dari Brown dkk. (2007). Pertanyaannya adalah "saya menghormati kepercayaan publik," "saya tulus dalam melayani publik," "diharapkan saya dapat memberikan layanan berkualitas kepada publik," "saya menunjukkan dedikasi terhadap keunggulan profesional," dan "saya melayani kepentingan publik." Skala Likert antara 1 = sangat tidak setuju dan $5=$ sangat setuju.

Variabel moderasi dalam penelitian ini adalah tekanan anggaran waktu. Tekanan anggaran waktu akan menggunakan pertanyaan yang diadopsi dari McNair (1991). Item-item tersebut adalah "Saya harus menghabiskan lebih banyak waktu daripada yang lain untuk menyelesaikan jumlah tugas yang sama," "Saya menyelesaikan sebagian besar tugas audit lebih cepat daripada auditor biasa dengan tingkat pengalaman yang saya miliki," dan "Saya biasanya menyelesaikan pekerjaan saya dalam alokasi anggaran waktu". Skala Likert antara 1 = sangat tidak setuju dan $5=$ sangat setuju.

Variabel dependen dari penelitian ini adalah independensi auditor. Pertanyaan ini diadopsi dari Yuen et al. (2013). Item pertanyaannya adalah "perusahaan saya telah menawarkan layanan kepada sebagian besar klien saya selama bertahun-tahun", "sebagian besar klien audit saya adalah perusahaan menengah hingga besar", "Saya memiliki hubungan yang erat dengan beberapa klien saya", dan "Saya benar-benar peduli dengan nasib klien saya". Skala Likert antara $1=$ sangat tidak setuju dan $5=$ sangat setuju.

\section{Analisis Statistik}

Alat yang digunakan untuk menguji hubungan yang telah dihipotesiskan adalah PLS (Partial Least Squares). Alasan penggunaan PLS adalah: pertama, variabel yang digunakan adalah variabel yang tidak dapat diobservasi (unobservable) atau variabel laten. Kedua, model penelitian akan menguji hubungan yang kompleks dengan menguji peran variabel moderasi. Asumsi ini sejalan dengan syarat penggunakan PLS seperti yang dikemukanan oleh Hair dkk. (2013) dan Sarstedt dkk. (2014). Penelitian ini akan menggunakan SmartPLS.

\section{HASIL DAN PEMBAHASAN}

\section{Statistik Desktiptif}

Dalam proses pengumpulan data, penelitian ini mendistribusikan 205 kuesioner ke auditor yang bekerja di kantor akuntan publik di Indonesia. Sebanyak 120 yang terkumpul, namun hanya 87 yang dapat diolah, sehingga respond rate hanya mencapai 72.5 persen. Dari total 87 responden, terdapat 39 persen berjenis kelamin laki-laki dan sisanya adalah responden perempuan. Persentasi tertinggi untuk usia adalah 94 persen yang berada diantara 20 - 30 tahun dengan pengalaman kerja antara 1 hingga 3 tahun (91 persen). Lebih dari 50 persen responden adalah auditor yang bekerja di kantor akuntan publik non-big 4, dan sisanya sebesar 49 persen berasal dari auditor Big 4. Secara detail, data demografik responden ditunjukkan pada table 1 di bawah ini: 
Tabel 1. Demografi Responden

\begin{tabular}{ll}
\hline & $\%$ \\
\hline $\begin{array}{l}\text { Jenis Kelamin } \\
\text { Laki-Laki }\end{array}$ & $39 \%$ \\
$\quad$ Perempuan & $61 \%$ \\
Usia & \\
$\quad<20$ Tahun & $1 \%$ \\
20 - 30 Tahun & $94 \%$ \\
31 - 40 Tahun & $4 \%$ \\
$\quad>40$ Tahun & $1 \%$ \\
Lama bekerja sebagai auditor & \\
$\quad$ - 3 Tahun & $91 \%$ \\
$\quad 4$ - 5 Tahun & $8 \%$ \\
$>5$ Tahun & $1 \%$ \\
KAP & \\
$\quad$ Big 4 & $49 \%$ \\
$\quad$ Non-Big 4 & $51 \%$ \\
\hline Sumber: olah data 2019 &
\end{tabular}

Tabel 2 dibawah ini menunjukkan nilai min, max, rata-rata, dan standar deviasi dari setiap variabel. Rata-rata nilai untuk variabel kepercayaan publik adalah 4.35, sedangkan independensi auditor dan tekanan anggaran waktu sebesar 3.81 dan 3.09. Untuk semua variabel memiliki nilai terendah 1 dan nilai tertinggi 5 .

Tabel 2. Statistik Deskriptif Variabel

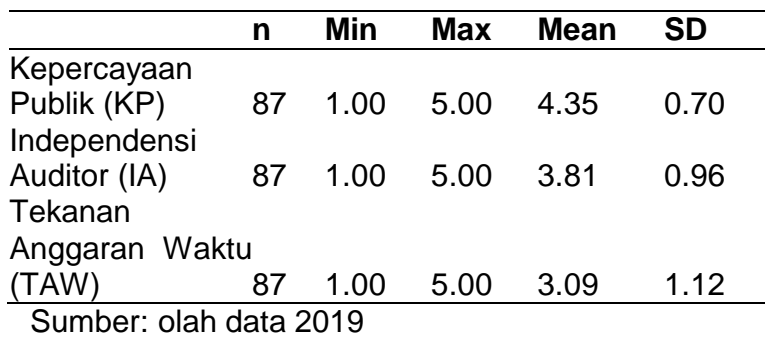

\section{Uji Validitas dan Reliabilitas}

Sebelum pengujian hipotesis, penelitian ini terlebih dahulu menguji validitas dan reliabilitas konstrak. Uji validitas dilakukan dengan menguji validitas konvergen dan validitas diskriminan. Sesuai dengan Hair dkk. (2013), uji validitas konvergen ditunjukkan oleh nilai loading dan nilai AVE (average variance extracted). Uji reliabilitas diperoleh dari nilai Cronbach Alpha dan Composite Reliability (CR) (Nunnaly, 1967). Hasil uji validitas dan reliabilitas diuraikan dalam tabel 3.

Tabel 3. Uji Validitas Convergen dan Reliabilitas

\begin{tabular}{|c|c|c|c|c|}
\hline & $\begin{array}{l}\text { Nilai } \\
\text { Loading }\end{array}$ & (CR) & $\begin{array}{l}\text { Cronbach } \\
\text { Alpha }\end{array}$ & (AVE) \\
\hline$\overline{\mathbf{K P}}$ & & 1.000 & 0.658 & 1.000 \\
\hline KP1 & 0.747 & & & \\
\hline KP2 & 0.646 & & & \\
\hline KP3 & 0.642 & & & \\
\hline KP5 & 0.773 & & & \\
\hline IA & & 0.796 & 1.000 & 0.496 \\
\hline $\mathrm{IA} 2$ & 1.000 & & & \\
\hline TAW & & 1.000 & 1.000 & 1.000 \\
\hline TAW2 & 1.000 & & & \\
\hline TAW $\times$ KP & & 0.722 & 0.688 & 0.404 \\
\hline $\begin{array}{l}\text { TAW1 } \\
\text { KP1 }\end{array}$ & $\times 0.627$ & & & \\
\hline $\begin{array}{l}\text { TAW1 } \\
\text { KP2 }\end{array}$ & $x 0.378$ & & & \\
\hline TAW1 & x0.679 & & & \\
\hline KP3 & & & & \\
\hline $\begin{array}{l}\text { TAW1 } \\
\text { KP5 }\end{array}$ & x0.649 & & & \\
\hline
\end{tabular}

Sedangkan untuk nilai validitas diskriminan, ditunjukkan dengan besarnya nilai square root AVE seperti yang ditunjukkan oleh tabel 4. Berdasarkan Fornell \& Larcker, (1981), nilai yang berada dalam posisi diagonal (nilai dalam bracket) harus lebih besar daripada di luar bracket. Tabel 4 juga menunjukkan hasil uji korelasi antar variabel kepercayaan publik, independensi auditor, dan tekanan anggaran waktu.

Tabel 4. Uji Validitas Diskriminan

\begin{tabular}{lllll}
\hline & KP & IA & TAW & $\begin{array}{l}\text { TAW } \\
\text { KP }\end{array}$ \\
\hline KP & $(0.705)$ & & & \\
IA & 0.301 & $(1.000)$ & & \\
TAW & 0.036 & 0.095 & $(1.000)$ & \\
TAW x KP & 0.261 & 0.261 & 0.322 & $(0.636)$ \\
\hline
\end{tabular}


Nilai di elemen diagonal adalah $\sqrt{ }$ AVE

Berdasarkan tabel 3 dan 4, maka dapat disimpulkan bahwa semua konstuk penelitian telah memenuhi syarat uji validitas dan reliabilitas.

\section{Analisis Model}

Hipotesis pertama menunjukkan hubungan langsung di antara kepercayaan publik dan independensi auditor. Gambar 2 menunjukkan hasil pengujian model moderasi dalam PLS. Tabel 5 merupakan hasil pengujian model mederasi yang membuktikan bahwa $\mathrm{H} 1$ terdukung secara statistik (t-stat lebih besar atau sama dengan 1.96, $p=0.001$ ). Hasil penelitian ini menunjukkan bahwa kepercayaan publik berpengaruh terhadap independensi auditor. Hipotesis kedua penelitian ini menunjukkan hubungan moderasi yaitu tekanan anggaran waktu terhadap hubungan antara kepercayaan publik dengan independensi auditor. Sementara, hasil penelitian menunjukkan bahwa tekanan anggaran waktu tidak berpengaruh terhadap hubungan antara kepercayaan publik dengan independensi auditor, $(p<0.275)$. Dengan demikian, H2 penelitian ini tidak terdukung.

Tabel 5. Tabel Hasil Uji Moderasi

\begin{tabular}{lll}
\hline & T-Stat & P Values \\
\hline KP $>$ IA & 2.599 & 0.001 \\
TAW $->$ IA & 0.117 & 0.907 \\
KP $\times$ TAW -> IA & 1.094 & 0.275 \\
\hline
\end{tabular}

Sumber: olah data 2019

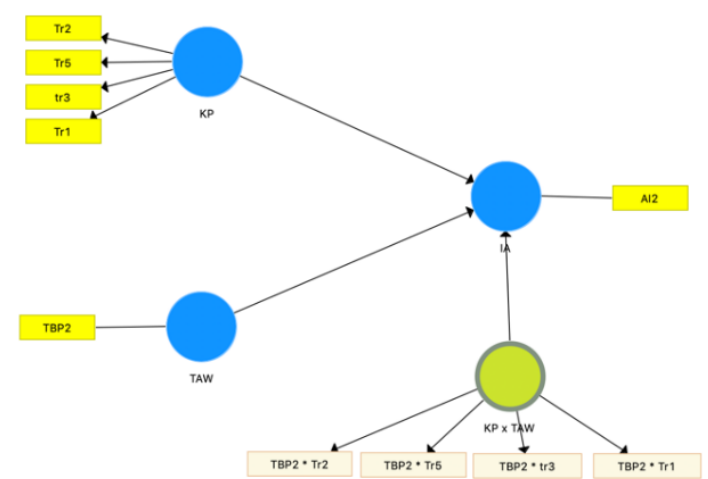

Gambar 2. Model Hasil Uji PLS

\section{Pembahasan}

Hasil pengujian hipotesis pertama penelitian ini adalah apakah kepercayaan publik secara positif berpengaruh terhadap independensi auditor. Penelitian ini menemukan hubungan di antara kepercayaan publik dan independensi auditor. Shaub (2015) menyatakan bahwa kepercayaan merupakan salah satu faktor yang dapat mengancam independensi auditor. Auditor yang menunjukkan kepercayaan yang lebih besar kepada klien umumnya kurang dalam menguji laporan klien dan lebih jarang menemui klien. Ia menyatakan bahwa kepercayaan auditor dapat berubah dari kepercayaan rasional menjadi kepercayaan emosional. Artinya semakin dekat hubungan auditor dengan klien akan menyebabkan auditor terikat secara personal dengan klien sehingga auditor cenderung untuk mensukseskan tujuan klien sesuai dengan permintaan klien. Hal ini dapat merusak independensi yang dimiliki oleh auditor. Hal ini sejalan dengan Elinor \& James (2013), mereka menyatakan bahwa kepercayaan adalah kemauan mengambil risiko tentang orang lain dengan harapan orang lain akan membalasnya. Definisi ini merepresentasikan bahwa kepercayaan akan menimbulkan kebergantungan satu sama lain dimana mereka ingin mendapatkan keuntungan satu sama lain. Hal ini jelas melanggar independensi yang 
harus dimiliki oleh seorang auditor. Berdasarkan hasil penelitian, peneliti memandang bahwa lamanya pengalaman kerja akan menunjukkan hasil yang berbeda pada hubungan kepercayaan publik dengan independensi auditor.

Hipotesis kedua penelitian ini adalah apakah tekanan anggaran waktu terhadap hubungan di antara kepercayaan publik dan independensi auditor. Penelitian ini menunjukkan tidak ada pengaruh antara tekanan anggaran waktu terhadap independensi auditor. Dapat dikatakan bahwa tekanan anggaran waktu bukan pemoderasi pengaruh antara kepercayaan publik dan independensi auditor. Auditor tetap mampu menjaga independensinya meskipun banyak tekanan pekerjaan yang diberikan kepada mereka. Penelitian ini memiliki mayoritas responden dengan rata-rata masa kerja 1 - 3 tahun. Mereka mampu menjaga independensi sebagai auditor.

\section{KESIMPULAN}

Penelitian ini menguji peran kepercayaan publik dan tekanan anggaran waktu terhadap independensi auditor. Penelitian ini menemukan bahwa tekanan anggaran waktu tidak berpengaruh terhadap hubungan antara kepercayaan publik dengan independensi auditor. Hal ini merepresentasikan jika hubungan kepercayaan publik dengan independensi auditor cenderung tidak dipengaruhi meskipun tekanan anggaran waktu hadir. Akan tetapi, penelitian ini tidak menemukan hubungan kepercayaan publik dengan independensi auditor.

Penelitian ini memiliki beberapa keterbatasan penelitian. Pertama, penelitian ini hanya dapat digeneralisasi dalam ruang lingkup dari sampel penelitian. Penelitian selanjutnya dapat meneliti kembali mengenai independensi auditor agar generalisasi dapat semakin kuat. Kedua, pengambilan data hanya disebar melalui media elektronik sehingga peneliti tidak dapat mengontrol penyebaran data secara langsung, seperti adanya pemusatan demografi disatu sisi. Mayoritas responden yang diperoleh memiliki rata-rata masa kerja 1-3 tahun. Penelitian selanjutnya, dapat menggunakan pengambilan data dengan media elektronik dan survei face to face. Ketiga, penelitian ini hanya meneliti faktor kepercayaan publik dan tekanan anggaran waktu, masih banyak faktor lainnya yang dapat mempengaruhi independensi auditor yang dapat diteliti lebih lanjut. Faktor tersebut antara lain, audit tenure, ukuran perusahaan, dan kualitas audit (Achyarsyah \& Molina, 2014).

\section{REFERENCES}

Achyarsyah, P., and Molina. (2014). Audit Firm Tenure, Audit Firm Size and Audit Quality. Global Journal of Business and Social Science Review, 69-76.

Arens, A.A., Loebbecke, J. K., Lemon, W. M. and Splettstoesser, I. B. (2002). Auditing and Other Assurance Services, 9th ed., Prentice-Hall, Toronto.

Bazerman, M. H., Morgan, K. P., and Loewenstein, G. F. (1997). The Impossibility of Auditor Independence. Sloan Management Review, 38 (4), 89-94.

Brown, P. A., Stocks, M., H., and Wilder, W. M. (2007). Ethical Exemplification and the AICPA Code of Professional Conduct: An Empirical Investigation of Auditor and Public Perceptions", Journal of Business Ethics, 71, 39 71 
Butler, J. K., and Cantrell, R. S. (1984). A Behavioral Decision Theory Approach to Modelling Dyadic Trust in Superiors and Subordinates. Psychological Reports, 19-28.

Carey, P., and Simnett, R. (2006). Audit Partner Tenure and Audit Quality. The Accounting Review, 81(3), 653676.

Cook, E., and Kelly, T. (1991). An International Comparison of Audit Time-Budget Pressures: The United States and New Zealand. The Woman CPA, 53(2), 25-30.

Cooper, C., Dewe, P., and O'Driscoll, M. (2001). Organizational Stress: $A$ Review and Critique of Theory, Research, and Applications. Thousand Oaks, California: Sage Publications.

Coram, P., Ng, J., and Woodliff, D. (2003). A Survey of Time Budget Pressure and Reduced Audit Quality among Australian Auditors. Australian Accounting Review, 13(1), 38-45.

Duska, R., Duska, B, S., and Ragatz. J, A. (2011). Accounting Ethics, 2nd Edition, Wiley-Blackwell.

Elinor, O., and James, W. (2003). Trust and Reciprocity: Interdisciplinary Lessons from Experimental Research. New York: Russel Sage Foundation.

Etteredge, M. L., Bedard, J. C., and Johnstone, K. M. (2008). Empirical Tests of Audit Budget Dynamics. Behavioral Research in Accounting, 20 (2), 1-18.

Falk, H., Lynn, B., Mestelman, S., and Shehata, M. (1999). Auditor Independence, Self-interested
Behaviour, and Ethics: Some Experimental Evidence. Journal of Accounting and Public Policy, 18, 395-428.

Fornell, C., \& Larcker, D. F. (1981). "Erratum: Structural Equation Models with Unobservable Variables and Measurement Error: Algebra and Statistics". Journal of Marketing Research, 18(3), 328-388.

Glover, S. (1997). The Influence of Time Pressure and Accountability on Auditors' Processing of NonDiagnostic Information. Journal of Accounting Research, 35(2), 213226.

Gundry, L., and Liyanarachchi, G. (2007). Time Budget Pressure, Auditors' Personality Type, and the Incidence of Reduced Audit Quality Practices. Pacific Accounting Review, 19(2), 125-152.

Hair, J. F., Hult, G. T., Ringle, C., and Sarstedt, M. (2013), A Primer on Partial Least Squares Structural Equation Modeling (PLS-SEM), SAGE Publications.

Hudaib, M., and Haniffa, R. (2009). Exploring Auditor Independence: an Interpretive Approach. Accounting, Auditing \& Accountability Journal, 22, 221-246.

International Ethics Standards Board for Accountants. (2012). Handbook of the code of ethics for professional accountants. Retrieved from http://www.ifac.org/sites/default/files/pu blications/files/2012IESBAHandbook.pdf

Kelley, T., and Margheim, L. (1990). The Impact of Time Budget Pressure, Personality, and Leadership Variables on Dysfunctional Auditor Behavior. Auditing: A Journal of Practice \& Theory, 9(2), 21-42. 
Liyanarachchi, G. A., and McNamara, S. M. (2007). Time Budget Pressure in NewZealand Audits. University of Auckland Business Review, 9 (2), 60-68.

McNair, C. (1991), "Proper Compromises: The Management Control Dilemma in Public Accounting and Its Impact on Auditor Behavior," Accounting, Organizations and Society, 16(7), 635-653.

Mohamed, D. M., and Habib, M H. (2013). Auditor Independence, Audit Quality and The Mandatory Auditor Rotation in Egypt. Education, business, and society: contemporary middle eastern, 6(2), 116-144.

Moore, D. A., Tetlock, P. E., Tanlu, L., and Bazerman, M. H. (2006). Conflicts of Interest and the Case of Auditor Independence: Moral Seduction A Strategic Issue Cycling. Academy of Management Review, 31 (1), 10.

Nunnaly, J. C. (1967). Psychometric Theory. New York: McGraw-Hill

Otley, D. T., and Pierce, B.J. (1996). Auditor Time Budget Pressure: Consequences and Antecedents. Accounting, Auditing \& Accountability Journal, 9 (1), 31-58.

Pierce, B., and Seeney, B. (2004). Cost-quality Conflict in Audit Firms: An Empirical Investigation. European Accounting Review, 13 (3), 779-812.

Porter, B., Simon, J. and Hatherly, D. (2003). Principles of External Auditing, John Wiley \& Sons, New York, NY.

Sarstedt, M., Ringle, C. M., Smith, D., Reams, R., and Hair, J. F. (2014), "Partial Least Squares Structural Equation Modeling (PLS-SEM): A Useful Tool for Family Business Researchers," Journal of Family Business Strategy, 5(1), 105-115.

Shaub, M. K. (2015). Trust as A Threat to Independence. Research on
Professional Responsibility and Ethics in Accounting, 9, 169-188.

Svanberg, J., and Ohman, P. (2013). Auditors' Time Pressure: Does Ethical Culture Support Audit Quality? Managerial Auditing Journal, 28(7), 572 - 591.

Svanstrom, T. (2016). Time Pressure, Training Activities, and Dysfunctional Auditor Behaviour: Evidence from Small Audit Firms. International Journal of Auditing, 20, 42-51.

Yuen, D. C. Y., Law, P. K. F., Lu, C., and Qi Guan, J. (2013). Dysfunctional Auditing Behavior: Empirical Evidence on Auditors' Behavior in Macau. International Journal of Accounting \& Information Management, 21 (3), 209226.

Zand, D. E. (1972). Trust and Managerial Problem Solving. Administrative Science Quarterly, 229-239. 